\title{
Freeze-Thaw Effects on Stability of Open Pit Slope in High- Altitude and Cold Regions
}

\author{
Yong Hong, ${ }^{1}$ Zhushan Shao $\mathbb{D},{ }^{1}$ Guangbin Shi, ${ }^{1}$ Yong Dou, ${ }^{2}$ Weiqin Wang, \\ and Wen Zhang ${ }^{1}$ \\ ${ }^{1} X i$ 'an University of Architecture and Technology, Xi'an, Shaanxi 710055, China \\ ${ }^{2}$ China Coal Xi'an Design Engineering Co., Ltd., Xi'an, Shaanxi 710055, China \\ Correspondence should be addressed to Zhushan Shao; shaozhushan@xauat.edu.cn
}

Received 23 August 2021; Revised 28 September 2021; Accepted 4 October 2021; Published 27 October 2021

Academic Editor: Yu Wang

Copyright (C) 2021 Yong Hong et al. This is an open access article distributed under the Creative Commons Attribution License, which permits unrestricted use, distribution, and reproduction in any medium, provided the original work is properly cited.

\begin{abstract}
The cycle of the freeze-thaw action must be taken into account in the stability analysis of an open pit slope in the high-altitude and cold regions, because the natural process of freeze-thaw poses a significant effect on mechanical properties of the rock mass. To achieve this purpose, a linear relationship between the geological strength index (GSI) and the Tianshan slope rock mass rating (TSMR) system is established considering the effect of the freeze-thaw action by introducing a freeze-thaw correction coefficient $\delta$. The GSI value is modified for rock mass in high-altitude and cold regions. The improved Hoek-Brown criterion considers the influences of the freeze-thaw action and steep and gentle slopes. The research outcome is applied in the No. 4 minefield open pit coal mine in the Muli mining area. Numerical calculations are performed by inputting rock mass mechanical parameters obtained in traditional and modified criterions, to discuss the influences of the freeze-thaw action on the stabilities of both the present mining slope and the final slope at the end of the designed mining. The results show that the safety factors of the original slope are 2.33 and 1.67, respectively, while after the modification, they are 2.14 and 1.61 , respectively. In terms of the No. 4 minefield open pit coal mine, the slope stability meets the design requirement, although taking the freeze-thaw cycle into account.
\end{abstract}

\section{Introduction}

Slope stability analysis has always been one of the basic problems in the field of geotechnical engineering. At present, some fruitful results have been achieved in the analysis of slope stability under normal temperature [1]. However, the research of rock slope stability under freeze-thaw cycles in cold regions is still in its infancy [2]. The freeze-thaw cycle normally causes the deterioration of mechanical properties of the rock mass [3-5], thus leading to slope instability. It is an urgent task to study the influence of the freeze-thaw action on rock slope stability.

Reasonable determination of rock mass mechanical parameters is the basis of slope stability analysis and slope treatment, and it is also one of the difficulties in rock mechanics research and development [6]. At present, many methods have been widely used to determine rock mechan- ical parameters [7-17]. Practice has proven that when rock mechanical parameters are modified and converted into rock mass mechanical parameters, the results could better meet the engineering needs [17]. Such modification is based on laboratory rock experiments and tests and by taking a comprehensive list of factors into account such as the types and characteristics of rock structural planes, stress state, rock disturbance, size effect, and groundwater. The Hoek-Brown criterion as a typical example has attracted wide attention from both academia and engineering geological fields, and it has been widely applied as well. Currently, it has become one of the most recommended methods by the International Society for Rock Mechanics and Rock Engineering (ISRM) [17-21].

The Hoek-Brown criterion could reflect the intrinsic and nonlinear failure characteristics of the rock and rock mass as well as the influence that the structural plane and stress state 


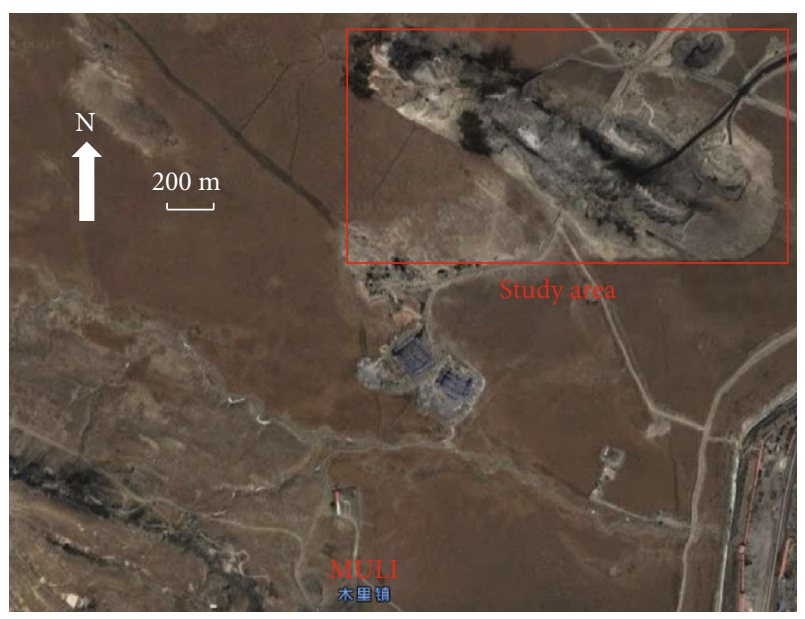

Figure 1: Location of the area under study.

exert on rock mass strength. It could also be used to explain the influence of the low stress zone, tension stress zone, and minimum principal stress on rock mass strength. In addition to the above, it can be extended to the description of the fractured rock mass and anisotropic rock mass. The latest edition is the generalized Hoek-Brown strength criterion $[18,21]$, which was proposed in 2002. In its expression, the disturbance factor $D$ which considers the effect of stress relaxation and near blast damage is introduced, and a parameter selection method based on the geological strength index (GSI) is proposed. The Hoek-Brown strength criterion is empirical. Determining the two parameters is crucially significant for selecting rock mass strength parameters. Hence, many scholars have carried out in-depth analysis and research on the values of $D$ and GSI $[22,23]$.

The freeze-thaw action causes damage to rocks and thus is not conducive to the stability of the rock slope. Under the action of freeze-thaw cycles, the rock mass undergoes freezethaw damage and its strength decreases. Especially for the fractured rock mass containing water, water-ice phase transformation occurs at low temperature. As the ice body grows and volume expands, tensile stress occurs around the pore and at the tip of the fracture, which causes rock mass frost heave and cracking. Recurrent freeze-thaw weakens the integrity and strength index of the rock mass. When the Hoek-Brown criterion is used to determine rock mass parameters, the effect of freeze-thaw cycles on GSI must be considered. At present, the experimental method is a major one applied to study the physical and mechanical properties of rock mass in cold regions. According to this method, the effects of freeze-thaw cycles on the physical and mechanical parameters of the rock mass under different conditions have been discussed. However, the problem remains unsolved regarding how to determine the mechanical parameters of the rock mass based on the experimental results.

This paper establishes the relationship between GSI and TSMR and presents an improved Hoek-Brown criterion. The proposed theoretical analysis is applied in an engineering case, well demonstrating the influence of freeze-thaw cycles on the slope stability. The outcome of this research is useful for the slope design of similar projects.
TABLE 1: Rock strength parameters after freeze-thaw tests.

\begin{tabular}{|c|c|c|c|}
\hline \multirow{2}{*}{$\begin{array}{l}\text { Number of freeze-thaw } \\
\text { cycles }\end{array}$} & \multicolumn{3}{|c|}{$\begin{array}{l}\text { Average saturated compressive strength } \\
\qquad(\mathrm{MPa})\end{array}$} \\
\hline & $\begin{array}{c}\text { Coarse } \\
\text { sandstone }\end{array}$ & $\begin{array}{l}\text { Fine } \\
\text { sandstone }\end{array}$ & $\begin{array}{l}\text { Muddy } \\
\text { siltstone }\end{array}$ \\
\hline 0 & 104.1 & 114.8 & 89.6 \\
\hline 30 & 90.1 & 98.8 & 73.1 \\
\hline 60 & 83.9 & 86.7 & 58.7 \\
\hline 90 & 74.2 & 79.6 & 50.1 \\
\hline 120 & 64.4 & 72.3 & 42.3 \\
\hline
\end{tabular}

TABLE 2: Freeze-thaw coefficients of rock samples.

\begin{tabular}{|c|c|c|c|}
\hline \multirow{2}{*}{$\begin{array}{l}\text { Number of freeze-thaw } \\
\text { cycles }\end{array}$} & \multicolumn{3}{|c|}{$\begin{array}{c}\text { Average saturated compressive strength } \\
(\mathrm{MPa})\end{array}$} \\
\hline & $\begin{array}{c}\text { Coarse } \\
\text { sandstone }\end{array}$ & $\begin{array}{c}\text { Fine } \\
\text { sandstone }\end{array}$ & $\begin{array}{l}\text { Muddy } \\
\text { siltstone }\end{array}$ \\
\hline$\overline{0}$ & 1 & 1 & 1 \\
\hline 30 & 0.87 & 0.95 & 0.82 \\
\hline 60 & 0.81 & 0.76 & 0.66 \\
\hline 90 & 0.71 & 0.69 & 0.56 \\
\hline 120 & 0.62 & 0.63 & 0.47 \\
\hline
\end{tabular}

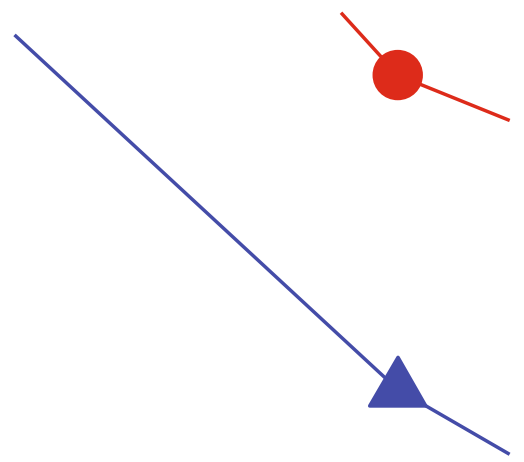

FIGURE 2: Relationship between freeze-thaw coefficients and freezethaw cycle times.

\section{Quality Evaluation of Rock Mass Slope in Cold Regions}

The No. 4 Minefield open pit coal mine is located in the Juhugeng Coal Mine Area in the Northeast of Qinghai Province. It is part of the Qinghai-Tibet Plateau. Its approximate location is shown in Figure 1. The highest altitude in the area is $4083.20 \mathrm{~m}$, and the lowest altitude is $3814.30 \mathrm{~m}$. The lowest temperature is mainly in January to February and the lowest recorded temperature is $-36^{\circ} \mathrm{C}$, whereas the highest temperature is in July to August with the highest recorded temperature of $19.8^{\circ} \mathrm{C}$. The annual average temperature is $-4^{\circ} \mathrm{C}$ and the annual average ground temperature is $-1.0^{\circ} \mathrm{C}$ to $-3.5^{\circ} \mathrm{C}$. Surface water freezes from October and thaws until April next year; as a result, it is below $0^{\circ} \mathrm{C}$ for nearly six months every year. The maximum seasonal freezing depth of the Muli mining area is about $8.25 \mathrm{~m}$. Because the 
TABLE 3: Corresponding relationship between rock uniaxial compressive strength, rock hardness, and rock freeze-thaw correction coefficients.

\begin{tabular}{|c|c|c|c|c|c|}
\hline Rock uniaxial compressive strength & $R_{c}>60 \mathrm{MPa}$ & $30 \mathrm{MPa}<R_{c} \leq 60 \mathrm{MPa}$ & $15 \mathrm{MPa}<R_{c} \leq 30 \mathrm{MPa}$ & $5 \mathrm{MPa}<R_{c} \leq 15 \mathrm{MPa}$ & $R_{c} \leq 5 \mathrm{MPa}$ \\
\hline Rock types & Hard rock & Relatively hard rock & Relatively soft rock & Soft rock & $\begin{array}{l}\text { Special soft } \\
\text { rock }\end{array}$ \\
\hline $\begin{array}{l}\text { Freeze-thaw correction coefficients } \\
(\delta)\end{array}$ & $\geq 0.9$ & $0.7-0.9$ & $0.5-0.7$ & $0.2-0.5$ & $\leq 0.2$ \\
\hline
\end{tabular}

TABLE 4: Freeze-thaw correction coefficients of rock mass in Muli mining area.

\begin{tabular}{lc}
\hline Lithology & Freeze-thaw correction coefficient \\
\hline Coarse sandstone & 0.9 \\
Fine sandstone & 0.85 \\
Muddy siltstone & 0.7 \\
\hline
\end{tabular}

coal mine is located in the permafrost area of the QinghaiTibet Plateau, the influence of freeze-thaw action on open pit slope stability must be considered.

2.1. Freeze-Thaw Coefficient. At present, the relevant regulations and standards about freeze-thaw tests in China are as follows: Rock Test Rules for Water Conservancy and Hydropower Engineering (SL264-2001), Rock Test Rules for Highway Engineering (JTGE41-2005), and Engineering Rock Test Method Standard (GBT 50266-2013). However, these codes and standards do not provide fully unified standards for the operation and requirements of freeze-thaw experiments, and due to lack of consistent understanding of freeze-thaw experiments at the international level, even the ISRM recommended standards for rock experiments are no exception.

According to the geological investigation report and the temperature variation pattern in the Muli mining area, the freeze-thaw cycling experiments were carried out with coarse sandstone, fine sandstone, and muddy siltstone as representative rock samples. The samples were set to freeze at $-25^{\circ} \mathrm{C}$ for 8 hours in a cryogenic refrigerator before being taken out. Lukewarm water would then be injected into the test box and the water temperature was kept at $25^{\circ} \mathrm{C}$ for 8 hours for sample thawing. The rock uniaxial compressive strength was measured after the freeze-thaw cycle times were set at $0,30,60,90$, and 120 . The experimental results are as shown in Table $1[24,25]$.

The definition of the rock freeze-thaw coefficient is consistent in the preceding specification standards. In this paper, the definition of the freeze-thaw coefficient is quoted from the Engineering Rock Mass Test Method Standard (GBT 50266-2013):

$$
K_{f m}=\frac{\bar{R}_{f m}}{\bar{R}_{w}},
$$

where $K_{f m}$ is the freeze-thaw coefficient of rock samples, $\bar{R}_{f m}$ is the average rock saturated uniaxial compressive strength after freeze-thaw cycles, and $\bar{R}_{w}$ is the average rock saturated uniaxial compressive strength before freeze-thaw cycle tests. The freeze-thaw coefficient of rock samples can be obtained as shown in Table 2 .

Table 2 shows that as the number of freeze-thaw cycle times increases; the freeze-thaw coefficients of the three kinds of rock samples gradually decreased to quite a different extent, which can also be seen from Figure 2. As a matter of fact, the freeze-thaw coefficients reflect the sensitivity of different rocks to freeze-thaw action. Specifically, the coefficient reduction of muddy siltstone is the largest, followed by coarse sandstone and fine sandstone. Since the influence of freeze-thaw action on rock mass quality is not limited to a single factor, it is necessary to modify the whole evaluation system before the introduction of the freeze-thaw coefficient. Therefore, the correction coefficient $\delta$ of rock freeze-thaw action is introduced to evaluate the influence of freezethaw action on rock mass quality. The quantification of the correction coefficients is mainly based on some existing rock freeze-thaw coefficient data. In addition, the hardness of rock mass, in combination with experience and field investigation, should also be considered.

The relationship between rock hardness, uniaxial compressive strength, and freeze-thaw correction coefficient is shown in Table 3. Combined with joint fissure investigation and uniaxial compression, the results suggest that coarse sandstone is hard rock and fine sandstone and muddy siltstone are relatively hard rock. The freeze-thaw correction coefficients are shown in Table 4.

2.2. Quality Classification of Slope Rock Mass. So far, many empirical rock mass quality classification systems have been put forward around the world. Some of them are directly or indirectly used in slope rock mass such as Q, RMR, MRMR, SMR, M-RMR, SRMR, and CSMR [26]. At present, there are still no relevant standard operational procedures and evaluation systems for slope engineering rock mass in open pit mines with high-altitude and cold conditions. The CSMR evaluation system introduces a height correction coefficient and structural plane correction coefficient, which are suitable for high slopes where hydropower projects are constructed. On this basis, Zhang et al. [27] introduced the freeze-thaw coefficient and established the rock mass quality evaluation system TSMR, which is suitable for highway slope engineering in a cold and high-altitude environment. Luo et al. [28], based on the TSMR evaluation system, analyzed the slope stability in the Mengku Iron Mine. No.4 minefield open pit mine in the Muli mining area which is located in high-altitude and cold areas, which meets the application conditions of the TSMR evaluation system. Hence, TSMR 
TABLE 5: Adjustment values of occurrence on discontinuous planes in Muli mining area.

\begin{tabular}{|c|c|c|c|c|c|c|}
\hline \multicolumn{2}{|c|}{ Condition } & Very favorable & Favorable & Ordinary & Unfavorable & Very unfavorable \\
\hline \multirow[t]{2}{*}{ Plane failure } & $\begin{array}{c}\left|\alpha_{j}-\alpha_{s}\right| \\
\left|\alpha_{j}-\alpha_{s}-180^{\circ}\right|\end{array}$ & $>30^{\circ}$ & $30^{\circ}-20^{\circ}$ & $20^{\circ}-10^{\circ}$ & $10^{\circ}-5^{\circ}$ & $<5^{\circ}$ \\
\hline & $F_{1}$ & 0.15 & 0.4 & 0.70 & 0.85 & 1.00 \\
\hline \multirow{2}{*}{ Plane failure } & $\left|\beta_{j}\right|$ & $<20^{\circ}$ & $20^{\circ}-30^{\circ}$ & $30^{\circ}-35^{\circ}$ & $35^{\circ}-45^{\circ}$ & $>45^{\circ}$ \\
\hline & $F_{2}$ & 0.15 & 0.4 & 0.70 & 0.85 & 1.00 \\
\hline \multirow{2}{*}{ Plane failure } & $\beta_{j}-\beta_{s}$ & $>10^{\circ}$ & $10^{\circ}-0^{\circ}$ & $0^{\circ}$ & $0^{\circ}-10^{\circ}$ & $<-10^{\circ}$ \\
\hline & $F_{3}$ & 0 & 6 & 10 & 25 & 30 \\
\hline
\end{tabular}

Note: $\alpha_{j}$ : discontinuous plane inclination; $\alpha_{s}$ : slope inclination; $\beta_{j}$ : discontinuous plane angle; $\beta_{s}$ : slope angle.

TABLE 6: TSMR values of slope rock mass in Muli mining area.

\begin{tabular}{lc}
\hline Lithology & TSMR values \\
\hline Coarse sandstone & 56 \\
Fine sandstone & 58 \\
Muddy siltstone & 50 \\
\hline
\end{tabular}

TABLE 7: GSI values of slope rock mass in Muli mining area.

\begin{tabular}{lc}
\hline Lithology & GSI \\
\hline Coarse sandstone & 51 \\
Fine sandstone & 53 \\
Muddy siltstone & 45 \\
\hline
\end{tabular}

is used herein to evaluate the rock mass quality in the No. 4 minefield open pit mine. The TSMR expression is as follows:

$$
\mathrm{TSMR}=\delta \xi \mathrm{RMR}-\lambda\left(F_{1} F_{2} F_{3}\right)+F_{4},
$$

where $\delta$ and $\xi$ are the freeze-thaw correction coefficient and slope height correction coefficient, respectively; $\xi=0.57+$ $0.43\left(H_{r} / H\right)$, where $H_{r}=80 \mathrm{~m}$ and $H$ is the slope height; $\lambda$ is the structural plane condition coefficient, and a geological report shows that there are faults in the mining area and $\lambda=1 ; F_{1}$ refers to the adjustment value of the dip direction between discontinuity and the slope surface; $F_{2}$ is the adjustment value of the dip angle of discontinuities; and $F_{3}$ is the adjustment value of the dip angle between discontinuity and the slope surface. The values of $F_{1}, F_{2}$, and $F_{3}$ are shown in Table 5. $F_{4}=10$ which is the adjustment factor of slope excavation and can be obtained through engineering practice experience and presplitting blasting. Based on Equation (2) and the correction of slope parameters, the TSMR calculation results of the slope rock mass are shown in Table 6.

\section{Rock Mass Quality Parameters of Open Pit Slope}

Since Hoek-Brown failure criterion was put forward in 1980 by E. Hoek and E. T. Brown, it has been widely applied in the field of rock mass engineering, and a series of practical engineering problems have been solved. At the same time, it has also attracted more scholars to conduct theoretical discussion. The latest version is expressed as follows [20]:

$$
\sigma_{1}=\sigma_{3}+\sigma_{c}\left(m_{b} \frac{\sigma_{3}}{\sigma_{c}}+s\right)^{a}
$$

$$
\begin{gathered}
m_{b}=m_{i} \exp \left(\frac{\mathrm{GSI}-100}{28-14 D}\right), \\
s=\exp \left(\frac{\mathrm{GSI}-100}{9-3 D}\right), \\
a=\frac{1}{2}+\frac{1}{6}\left(e^{-\mathrm{GSI} / 15}-e^{-20 / 3}\right),
\end{gathered}
$$

where $\sigma_{1}$ and $\sigma_{3}$ are the major and minor principal stresses, respectively; $\sigma_{c}$ is the uniaxial compressive strength of the intact rock; $m_{b}, s$, and $a$ are the empirical parameters reflecting rock mass characteristics; the value of $m_{i}$ is 13,15 , and 5 for coarse sandstone, fine sandstone, and muddy siltstone, respectively; $D$ is the disturbance factor, which is related to the rock mass excavation mode and disturbance degree. The research object herein is located in a large open pit coal mine and is excavated by blasting, so $D=1$; GSI is the geological strength index for short. With regard to the determination of the GSI value, Hoek, Kaiser, and Brown established the relationship between the GSI and RMR values, namely,

$$
\begin{aligned}
& \mathrm{GSI}=\mathrm{RMR}_{76}, \mathrm{RMR}_{76}>18, \\
& \mathrm{GSI}=\mathrm{RMR}_{89}-5, \mathrm{RMR}_{89}>23,
\end{aligned}
$$

where $\mathrm{RMR}_{76}$ and $\mathrm{RMR}_{89}$ are rock mass classification systems established by Bieniawski in 1976 and 1989, respectively. Based on the RMR system, TSMR is a rock mass quality evaluation method that takes into account the freeze-thaw behavior, rock mass structure, and slope height. Therefore, for rock mass slope engineering in cold and highaltitude regions, the GSI value can be expressed as follows:

$$
\mathrm{GSI}=\mathrm{TSMR}_{76}, \mathrm{TSMR}_{76}>18,
$$


TABLE 8: Strength parameters of rock mass on No. 4 minefield slope under freeze-thaw environment.

\begin{tabular}{|c|c|c|c|c|c|c|c|}
\hline \multirow[b]{2}{*}{ Lithology } & \multicolumn{2}{|c|}{ Internal friction angle $\varphi\left(^{\circ}\right)$} & \multicolumn{2}{|l|}{ Cohesion $c(\mathrm{MPa})$} & \multirow[b]{2}{*}{$\begin{array}{l}\text { Poisson } \\
\text { ratio }\end{array}$} & \multirow{2}{*}{$\begin{array}{l}\text { Deformation modulus } \\
E(\mathrm{GPa})\end{array}$} & \multirow{2}{*}{$\begin{array}{l}\text { Unit weight } \\
\left(\mathrm{kN} / \mathrm{m}^{3}\right)\end{array}$} \\
\hline & $\begin{array}{l}\text { Improved Hoek-Brown } \\
\text { criterion }\end{array}$ & RocLab & $\begin{array}{l}\text { Improved Hoek-Brown } \\
\text { criterion }\end{array}$ & RocLab & & & \\
\hline $\begin{array}{l}\text { Coarse } \\
\text { sandstone }\end{array}$ & 44.5 & 37.8 & 0.412 & 0.669 & 0.17 & 5.25 & 26.89 \\
\hline $\begin{array}{l}\text { Fine } \\
\text { sandstone }\end{array}$ & 49.9 & 42.1 & 0.259 & 0.436 & 0.20 & 4.89 & 26.39 \\
\hline $\begin{array}{l}\text { Muddy } \\
\text { siltstone }\end{array}$ & 36.9 & 22.8 & 0.249 & 0.270 & 0.19 & 2.66 & 26.59 \\
\hline
\end{tabular}
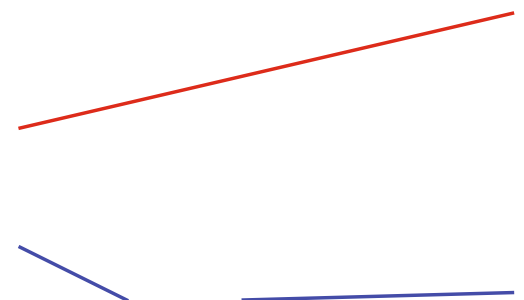

Figure 3: Comparison of rock mass internal friction angle and cohesion obtained by two methods.

$$
\mathrm{GSI}=\mathrm{TSMR}_{89}-5, \mathrm{TSMR}_{89}>23 .
$$

The GSI values of different lithologies in the No. 4 minefield open pit coal mine of the Muli mining area can be obtained from the above equation. The results are tabulated in Table 7.

In addition, in 2002, Hoek also gave the estimation equation of the deformation modulus of rock mass.

$$
\begin{aligned}
& E=\left(1-\frac{D}{2}\right) \sqrt{\frac{\sigma_{c}}{100}} 10^{(\mathrm{GSI}-10) / 40}\left(\sigma_{c i}<100 \mathrm{MPa}\right), \\
& E=\left(1-\frac{D}{2}\right) 10^{(\mathrm{GSI}-10) / 40}\left(\sigma_{c i}>100 \mathrm{MPa}\right) .
\end{aligned}
$$

In the stability analysis of rock slope engineering, the limit equilibrium method and many kinds of numerical software are based on the Mohr-Coulomb failure criterion. On the basis of the strength parameters of the Hoek-Brown criterion, E. Hoek proposed the following expressions for calculating the internal friction angle and cohesion of the Mohr-Coulomb criterion:

$$
c=\frac{\sigma_{c}\left[(1+2 a) s+(1-a) m_{b} \sigma_{3 n}\right]\left(s+m_{b} \sigma_{3 n}\right)^{a-1}}{(1+a)(2+a) \sqrt{1+6 a m_{b}\left(s+m_{b} \sigma_{3 n}\right)^{a-1} /[(1+a)(2+a)]}},
$$

$$
\varphi=\sin ^{-1}\left[\frac{6 a m_{b}\left(s+m_{b} \sigma_{3 n}\right)^{a-1}}{2(1+a)(2+a) 6 a m_{b}\left(s+m_{b} \sigma_{3 n}\right)^{a-1}}\right],
$$

where $\sigma_{3 n}=\sigma_{3 \max } / \sigma_{c}$, and the relationship between $\sigma_{3 \max }$, the upper limit of the confining stress, and $\sigma_{c m}$, the rock mass strength, is as follows:

$$
\frac{\sigma_{3 \max }}{\sigma_{c m}}=k\left(\frac{\sigma_{c m}}{\gamma H}\right)^{m}
$$

where $k$ and $m$ are empirical parameters, $\gamma$ is the unit weight of rock mass, and $H$ is the engineering burial depth. The compressive strength of the rock mass can be determined as

$$
\sigma_{c m}=\sigma_{c} \frac{\left[m_{b}+4 s-a\left(m_{b}-8 s\right)\right]\left(m_{b} / 4+s\right)^{a-1}}{2(1+a)(2+a)} .
$$

In slope engineering, $\mathrm{Li}$ et al. [29] have corrected the values of $k$ and $m$ in Equation (15) based on the limit analysis method. The modified $k$ and $m$ are 0.2 and -1.07 for the steep slope and 0.41 and -1.23 for the gentle slope.

According to the above expressions, the rock mass mechanical parameters of the No. 4 minefield open pit coal mine in the Muli mining area are determined as shown in Table 8. At the same time, the calculated results herein are compared with those obtained by generalized the HoekBrown criterion, and the latter are calculated using RocLab software. Figure 3 shows that the internal friction angle of the rock mass calculated in this paper is larger than that calculated by the generalized Hoek-Brown criterion. The reason is that under the influence of the freeze-thaw action, rock mass damage occurs inducing new cracks. As a consequence, the joint surface of rock mass becomes rougher, and the internal friction angle of the rock mass becomes larger. The case is especially true for muddy siltstone. Because of freeze-thaw susceptibility, the numerical results obtained through the two methods are quite different. As can be seen from Figure 3, as a result of the freeze-thaw action, the overall strength of rock mass decreases, and the calculated cohesion values are smaller than that calculated by the generalized Hoek-Brown criterion.

\section{Engineering Application}

4.1. Engineering Survey. The lithology of the strata in the No. 4 minefield open pit coal mine is mainly fine sandstone, coarse sandstone, and muddy siltstone. The present situation of open pit mining is shown in Figure 4. The minimum mining elevation is $+4000 \mathrm{~m}$ and the maximum mining depth is $135 \mathrm{~m}$. The stability analysis herein is made according to the geological environment conditions, the present production situation of open pit mine, and the structural 


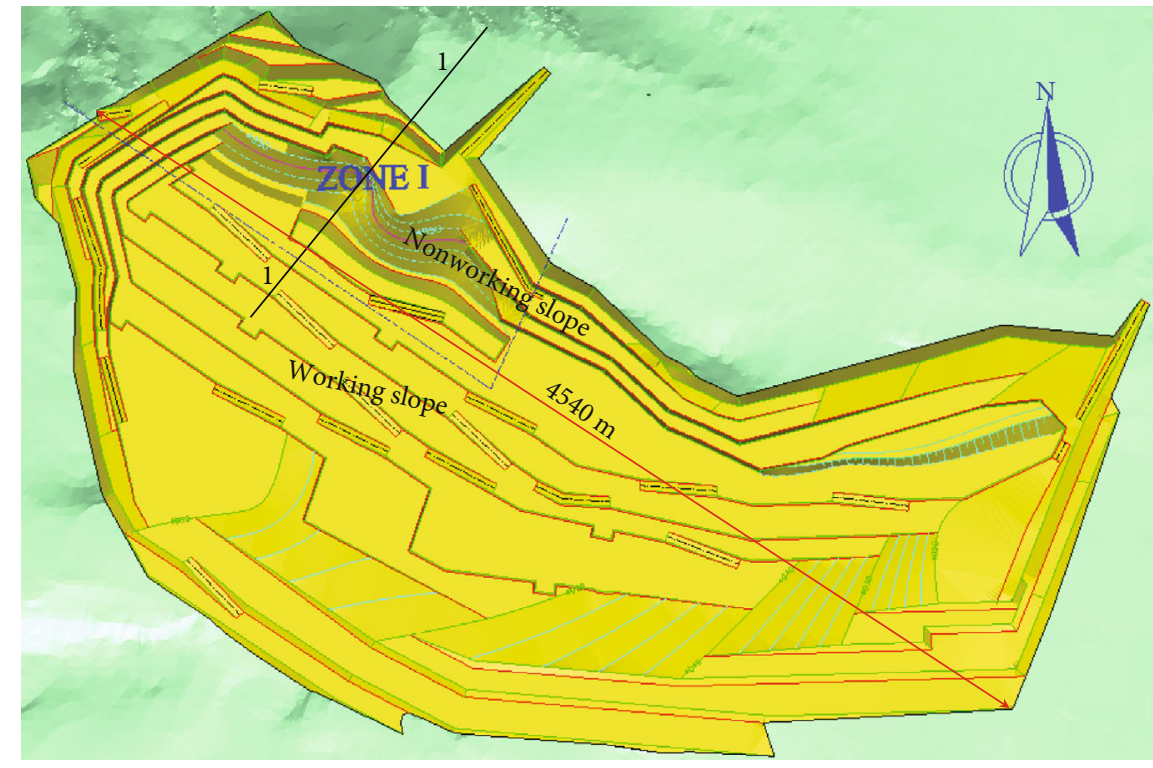

FIGURE 4: Present situation of open pit mine.

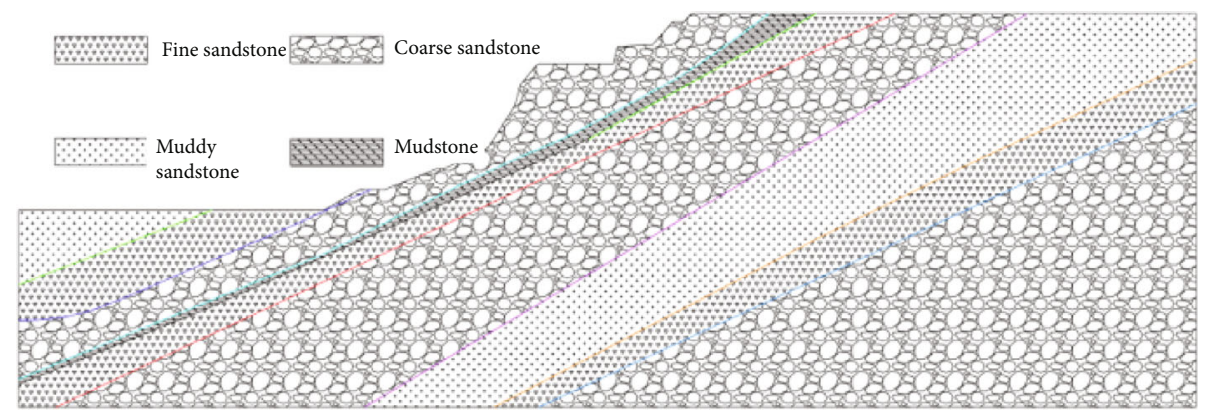

FIGURE 5: Profile of nonworking slope under the present open pit mining situation.

TABLE 9: Strength parameters of mudstone rock mass on No. 4 minefield slope.

\begin{tabular}{lccccc}
\hline Lithology & $\begin{array}{c}\text { Deformation } \\
\text { modulus } E \\
(\mathrm{GPa})\end{array}$ & $\begin{array}{c}\text { Internal } \\
\text { friction } \\
\text { angle } \varphi \\
\left({ }^{\circ}\right)\end{array}$ & $\begin{array}{c}\text { Cohesion } \\
c(\mathrm{MPa})\end{array}$ & $\begin{array}{c}\text { Poisson } \\
\text { ratio }\end{array}$ & $\begin{array}{c}\text { Unit } \\
\text { weight } \\
(\mathrm{kN} /\end{array}$ \\
\hline Mudstone & 2.78 & 21.4 & 0.220 & 0.25 & 23.42 \\
\hline
\end{tabular}

characteristics of the slope rock mass. More specifically, the working slope is a mining face with a small slope angle of about 12 degrees and good stability, so it is not considered. Likewise, the end slope is clamped and its stability is good, so it is not considered either. However, the nonworking slope has a larger slope angle and higher slope height in comparison with the working slope and the end slope. On top of this, a complete working platform has not yet been formed in Zone I, and the north slope suffered from landslides, hence resulting in its poor stability. Therefore, the present slope stability analysis is conducted at the 1-1 typical section of Zone I, which is located on the north side of the nonworking slope. Such stability analysis is also conducted for the final slope angle designed for the end of mining.

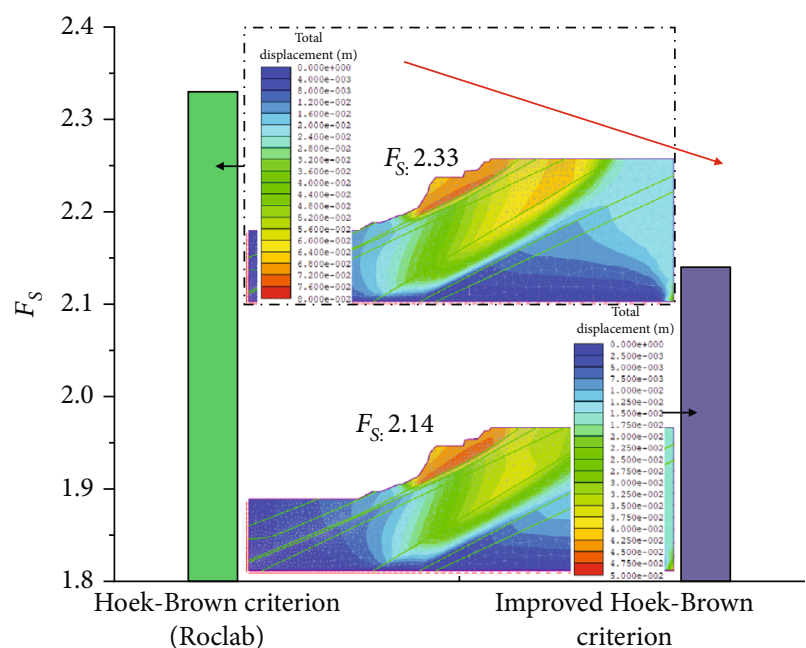

FIgURE 6: Slope safety factor and total displacement of the present nonworking slope in open pit mining (by RocLab and improved Hoek-Brown criterion).

4.2. Stability Analysis of Present Slope. According to the geological profile and rock mass structure characteristics, the typical section of the nonworking slope at Zone I is shown 


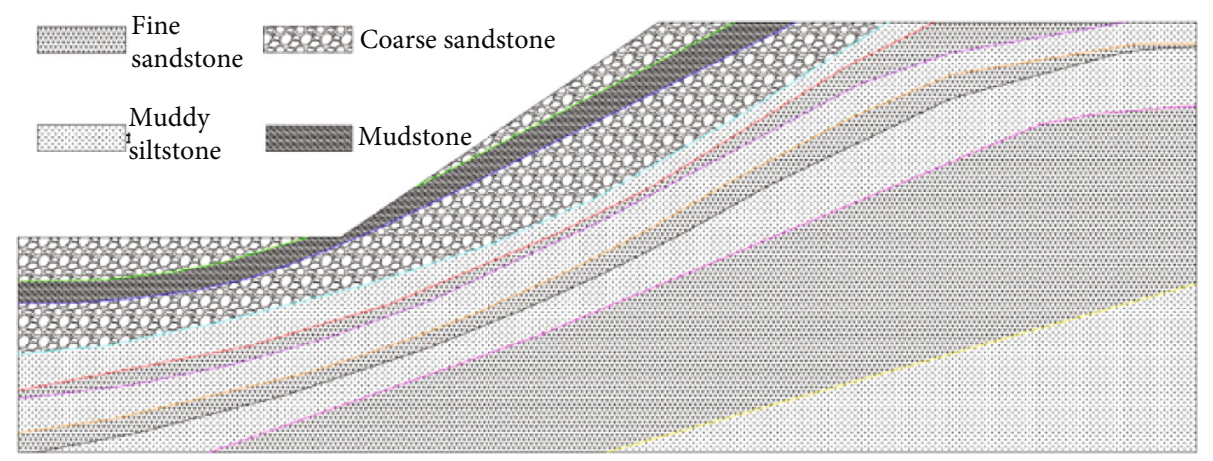

Figure 7: Profile of nonworking slope at the end of designed mining.

in Figure 5. The model contains a group of weak planes with mudstone as lithology, and its strength parameter is shown in Table 9. The height of the model slope is $94 \mathrm{~m}$. With the influence of the boundary area of the model on the calculation results considered, the distance from the bottom to the left boundary is $145 \mathrm{~m}$, the top to the right boundary is $240 \mathrm{~m}$, and the total height of the model is $188 \mathrm{~m}$ [30]. Phase 2 (Ver.8.014) software is used to establish a model and analyze the slope stability. After meshing, there are 5830 units and 3042 nodes. The slope surface is a free boundary, with the bottom boundary of the model fixed, and the left and right end boundaries constrained horizontally. The rock mass parameters calculated by the two methods in Table 8 are entered into the model for analysis and calculation, and the slope safety factor is calculated by the strength reduction method. The slope safety factors are 2.33 and 2.14 , respectively, based on the rock mass parameters obtained by using RocLab software and the improved Hoek-Brown criterion. The reason for the difference is that the rock mass strength is reduced by freeze-thaw action, which is consistent with the previous analysis. On the whole, no matter which method is used to calculate the rock mass parameters, the safety factor of the present slope is highly larger than specification requirements. This is because the present slope angle is small, about 28 degrees; therefore, the safety factor is large and the stability of the slope is good. The overall displacement and meshing of the slope calculated by the two methods are shown in Figure 6. It shows that the maximum displacements are $8 \mathrm{~cm}$ and $5 \mathrm{~cm}$, respectively, both occurring on steep slopes and weak layers. The analysis shows that although freeze-thaw cycling reduces the strength of rock mass, the slope angle of the nonworking side is relatively gentle, so the safety factor of the slope is large and the stability of the slope is good.

4.3. The Final Slope Stability Analysis of Open Pit Mine. The final slope angle of the open pit mine is a significant technical parameter, which directly affects the safety and economic benefits of the mine [30-38]. In the design process of the No.4 minefield open pit mine, a technical study is carried out to the final slope angle. In the study of slope engineering stability, when mining to the designed mining depth (slope height of $160 \mathrm{~m}$ ), the final slope angle is recommended to be 34 degrees. The current working conditions are the same

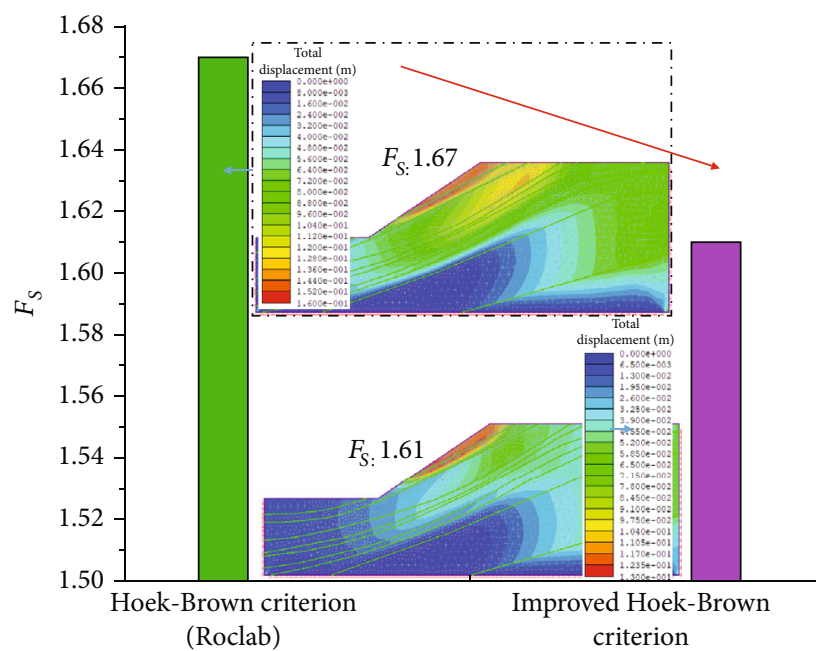

FIGURE 8: Slope safety factor and total displacement of nonworking slope at the end of designed mining (by RocLab and improved Hoek-Brown criterion).

as in the research report. A typical section of the northern slope (Zone I) is selected as the study section (Figure 7). Finite element model is established. The model parameters are the same as that of the present slope as mentioned earlier. The calculation results are shown in Figure 8. The slope safety factors are 1.67 and 1.61, respectively, based on the rock mass parameters obtained by using RocLab software and the improved Hoek-Brown criterion. The maximum displacement is $16 \mathrm{~cm}$ and $13 \mathrm{~cm}$, respectively. The analysis indicates that the safety factor of the slope calculated by the improved Hoek-Brown criterion decreased. The reasons and rules are also due to the freeze-thaw action, which reduces the strength of the rock mass. The seasonal freezing depth of the Muli mining area is about $8.25 \mathrm{~m}$. Considering the influence of moisture migration and blasting vibration, the slope is stable when the final slope angle is 34 degrees, and the slope angle design is relatively reasonable.

4.4. Discussion. Figure 9 presents the calculation process of modified rock mass parameters. The freeze-thaw correction coefficient is introduced to obtain the modified rock mass TSMR values. The linear relationship between TSMR and GSI is established to further achieve the values of other 


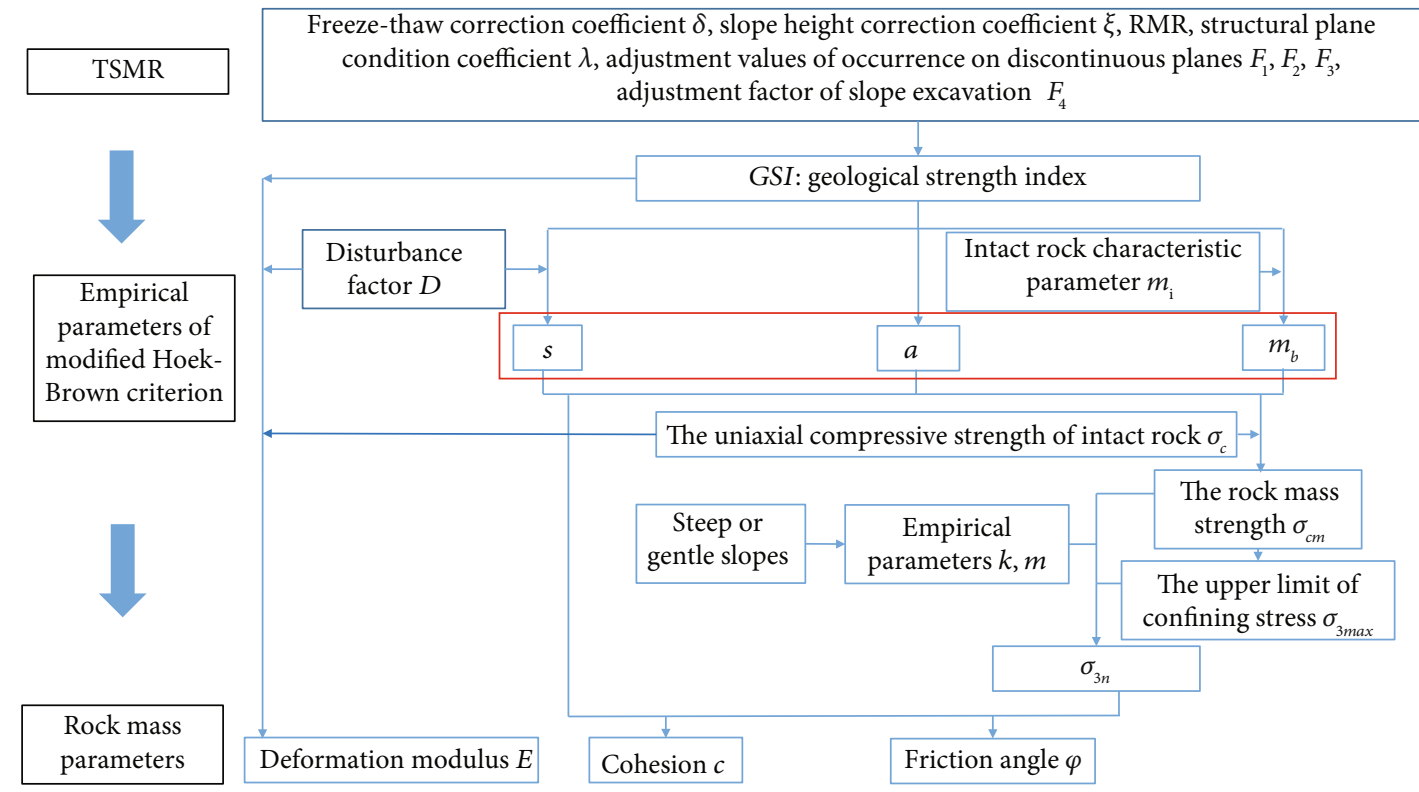

Figure 9: Calculation process of rock mass parameters.

parameters in the Hoek-Brown criterion. In addition, the values of empirical parameters $k$ and $m$ are corrected for the steep slope and the gentle slope. Then, equivalent conversion of the Hoek-Brown criterion to Mohr-Coulomb criterion is performed. Finally, the values of the rock mass parameters in the numerical calculation are obtained. All the parameters of the Hoek-Brown criterion are corrected throughout the calculation process, because the freeze-thaw correction coefficient is introduced at the beginning. The modified rock mass parameters can better describe the mechanical properties of slopes in high-altitude and cold regions. Absolutely, the correction of the empirical parameters $k$ and $m$ has more conformity with the actual slope engineering of the open pit mine.

As shown in Figures 6 and 8, it can be seen that after considering freeze-thaw action, the slope safety factor decreases by $8.15 \%$ and $3.59 \%$, respectively. The decreased slope safety factor may affect the magnitude of slope inclination in slope design. Generally, the slope inclination is designed as large as possible for the economic benefit, when considering the specification requirements and safety premise. The reduction of slope inclination caused by the decreases of the slope safety factor can also affect the mine production. In addition, it can be seen from Figure 2 that the rock freeze-thaw coefficient decreases as the number of freeze-thaw cycles increases, which generally shows that the freeze-thaw coefficient is reduced with the decrease of the rock strength. It can be seen from Figure 3 that when the freeze-thaw action is considered, the internal friction angle of the rock increases, while the cohesion decreases. Comprehensive analysis shows that under the effect of freeze-thaw of rock, the water-ice phase change causes the initial fractures of rock. The initiated cracks then expand until new fractures are formed. The forming of the new cracks may increase the roughness of rock joints which increase the internal friction angle and decreases the cohesion. However, the overall integrity is of the rock destroyed by the forming of the new fractures, thus reducing its mechanical properties. Since the freezethaw actions have significant effects on the slope stability, the freeze-thaw effects should be involved in the design process of the slope as well as production despite the effects of slope height, slope inclination, and slope rock parameters on slope stability.

\section{Conclusions}

According to the characteristics of freeze-thaw effects on rock mass in high-altitude and cold regions, mechanical parameters of rock mass are calculated and determined based on the improved Hoek-Brown criterion. The No. 4 minefield open pit coal mine in the Muli mining area is taken as an engineering case, and the differences between the traditional method and the modified method in calculating slope stability are compared and analyzed. The main conclusions are drawn as below:

(1) The experimental results show that the strength parameters of rock mass decrease under the situation of freeze-thaw cycles, after 120 freeze-thaw cycles, leading to the freeze-thaw coefficients of coarse sandstone, fine sandstone, and muddy siltstone decreasing to $0.62,0.63$, and 0.47 , respectively

(2) The Hoek-Brown criterion is modified based on the linear relationship between TSMR and GSI in the Hoek-Brown criterion and by considering whether the slope is steep or gentle. According to the correlation between the Hoek-Brown criterion and the Mohr-Coulomb criterion, mechanical parameters of the slope rock mass are determined in open pit mines in the case of freeze-thaw cycles. Based on 
improved calculation results, the internal friction angle of the rock mass is increases by $17.7 \%, 18.5 \%$, and $61.8 \%$, and the cohesion is decreased by $38.4 \%$, $40.6 \%$, and $7.8 \%$, respectively

(3) The slope stability in the open pit mine slope is calculated considering the effects of freeze-thaw. The calculated results show that in terms of the current slope, the safety factor of its nonworking slope is 2.14 , and the maximum displacement occurred at the steep slope and weak surface with the values of $5 \mathrm{~cm}$. At the end of mining, the slope safety factor is 1.61 , and the maximum displacement is $13 \mathrm{~cm}$. These decrease the slope safety factor by $8.15 \%$ and $3.59 \%$. The improved calculation method of rock mass parameters can quantitatively reflect the influence law of freeze-thaw on rock mass strength. Compared with the traditional method, the calculated safety factor of the slope is more consistent with the reality of the open pit slope in high-altitude and cold regions. The improved calculation method provides theoretical guidance for the design and evaluation of an open pit slope

\section{Data Availability}

The data used to support the findings of this study are available from the corresponding author upon request.

\section{Conflicts of Interest}

The authors declare that they have no conflicts of interest.

\section{Acknowledgments}

The authors would like to thank the financial support provided by the National Natural Science Foundation of China (Grant no. 11872287, 51904220), Natural Science Foundation of Shaanxi Provincial Department of Education (Grant no. 21JK0719), and Science and Technology Foundation of Xi'an University of Architecture and Technology (Grant no. ZR19063).

\section{References}

[1] Y. Hong, Z. S. Shao, G. B. Shi, and J. Liu, "Stability and countermeasures for a deposit slope with artificial scarp: numerical analysis and field monitoring," Advances in Civil Engineering, vol. 2020, Article ID 8822080, 13 pages, 2020.

[2] Q. S. Liu, S. B. Huang, Y. S. Kang, and X. Z. Cui, "Advance and review on freezing-thawing damage of fractured rock," Chinese Journal of Rock Mechanics and Engineering, vol. 34, no. 3, pp. 452-471, 2015.

[3] S. B. Huang, Y. Z. Liu, Y. L. Guo, Z. Zhang, and Y. Cai, "Strength and failure characteristics of rock-like material containing single crack under freeze-thaw and uniaxial compression," Cold Regions Science and Technology, vol. 162, pp. 110, 2019.

[4] Y. Wang, Y. F. Yi, C. H. Li, and J. Q. Han, "Anisotropic fracture and energy characteristics of a Tibet marble exposed to multi-level constant-amplitude (MLCA) cyclic loads: a lab- scale testing," Engineering Fracture Mechanics, vol. 244, article 107550, 2021.

[5] Y. Wang, B. Zhang, B. Li, and C. H. Li, “A strain-based fatigue damage model for naturally fractured marble subjected to freeze-thaw and uniaxial cyclic loads," International Journal of Damage Mechanics, vol. 30, article 105678952110216, 2021.

[6] K. Wu, Z. Shao, S. Qin, N. Zhao, and Z. Chu, "An improved non-linear creep model for rock applied to tunnel displacement prediction," International Journal of Applied Mechanics, vol. 13, article 2150094, 2021.

[7] M. G. Culshaw and R. Ulusay, "The ISRM suggested methods for rock characterization, testing and monitoring: 2007-2014," Bulletin of Engineering Geology and the Environment, vol. 74, no. 4, pp. 1499-1500, 2015.

[8] H. Zheng, X. T. Feng, Z. Y. Chen, J. A. Hudson, and Y. Wang, "ISRM suggested method for reporting rock laboratory test data in electronic format," Rock Mechanics and Rock Engineering, vol. 47, no. 1, pp. 221-254, 2014.

[9] D. Mas Ivars, M. E. Pierce, C. Darcel et al., "The synthetic rock mass approach for jointed rock mass modelling," International Journal of Rock Mechanics \& Mining Sciences, vol. 48, no. 2, pp. 219-244, 2011.

[10] K. Wu, Z. Shao, M. Sharifzadeh, Z. Chu, and S. Qin, “Analytical approach to estimating the influence of shotcrete hardening property on tunnel response," Journal of Engineering Mechanics, vol. 148, pp. 1-10, 2022.

[11] Z. T. Bieniawski, "Engineering classification of jointed rock masses," Civil Engineer in South Africa, vol. 15, no. 12, pp. 335-343, 1973.

[12] E. Hoek, P. K. Kaiser, and W. F. Bawden, Support of Underground Excavations in Hard Rock, A A Balkema Publishers, Rotterdam, Netherlands, 1st edition, 2000.

[13] N. Barton, "Some new Q-value correlations to assist in site characterisation and tunnel design," International Journal of Rock Mechanics and Mining Sciences, vol. 39, no. 2, pp. 185216, 2002.

[14] E. Hoek and E. T. Brown, "Practical estimates of rock mass strength," International Journal of Rock Mechanics and Mining Sciences, vol. 34, no. 8, pp. 1165-1186, 1997.

[15] E. Hoek and M. S. Diederichs, "Empirical estimation of rock mass modulus," International Journal of Rock Mechanics \& Mining Sciences, vol. 43, no. 2, pp. 203-215, 2006.

[16] I. Yilmaz and A. G. Yuksek, "An example of artificial neural network (ANN) application for indirect estimation of rock parameters," Rock Mechanics and Rock Engineering, vol. 41, no. 5, pp. 781-795, 2008.

[17] K. Wu, Z. Shao, M. Sharifzadeh, S. Hong, and S. Qin, "Analytical computation of support characteristic curve for circumferential yielding lining in tunnel design," Journal of Rock Mechanics and Geotechnical Engineering, vol. 14, pp. 1-9, 2022.

[18] E. Hoek and E. T. Brown, "Empirical strength criterion for rock masses," Journal of Geotechnical Engineering Division, vol. 106, no. 9, pp. 1013-1035, 1980.

[19] E. Hoek, D. Wood, and S. Shah, "A modified Hoek-Brown failure criterion for jointed rock masses," in Rock Characterization: ISRM Symposium, Chester, UK, September 1992, Thomas Telford Publishing, 1992.

[20] E. Hoek, C. Carranza-Torres, and B. Corkum, "Hoek-Brown failure criterion-2002 edition," Proceedings of NARMS-Tac, vol. 1, no. 1, pp. 267-273, 2002. 
[21] E. Eberhardt, "The Hoek-Brown failure criterion," Rock Mechanics \& Rock Engineering, vol. 45, no. 6, pp. 981-988, 2012.

[22] H. Sonmez and R. Ulusay, "Modifications to the geological strength index (GSI) and their applicability to stability of slopes," International Journal of Rock Mechanics and Mining Sciences, vol. 36, no. 6, pp. 743-760, 1999.

[23] W. K. Feng, S. Dong, Q. Wang, X. Yi, Z. Liu, and H. Bai, "Improving the Hoek-Brown criterion based on the disturbance factor and geological strength index quantification," International Journal of Rock Mechanics and Mining Sciences, vol. 108, pp. 96-104, 2018.

[24] S. H. Xu, N. Li, X. D. Wang et al., "Damage test and degradation model of saturated sandstone freezing and thawing of rock slopes of open-pit coal mine," Chinese Journal of Rock Mechanics and Engineering, vol. 35, no. 12, pp. 2561-2571, 2016.

[25] B. Y. Deng, Research of stability for the Muli slope of open-pit coal mine on freezing-thawing cycle, Xi' an University of Technology, Xi'an, China, 2015.

[26] L. Pantelidis, "Rock slope stability assessment through rock mass classification systems," International Journal of Rock Mechanics \& Mining Sciences, vol. 46, no. 2, pp. 315-325, 2009.

[27] Y. C. Zhang, R. Q. Huang, L. D. Zhao, R. H. Fu, and X. J. Pei, "Study of Tianshan slope rock mass rating (TSMR) system," Chinese Journal of Rock Mechanics and Engineering, vol. 29, no. 3, pp. 617-623, 2010.

[28] X. D. Luo, N. Jiang, X. Y. Fan, N. Mei, and H. Luo, "Effects of freeze-thaw on the determination and application of parameters of slope rock mass in cold regions," Cold Regions Science and Technology, vol. 110, pp. 32-37, 2015.

[29] A. J. Li, R. S. Merifield, and A. V. Lyamin, "Stability charts for rock slopes based on the Hoek-Brown failure criterion," International Journal of Rock Mechanics \& Mining Sciences, vol. 45, no. 5, pp. 689-700, 2008.

[30] Y. R. Zheng and S. Y. Zhao, "Application of strength reduction FEM in soil and rock slope," Chinese Journal of Rock Mechanics and Engineering, vol. 23, no. 19, pp. 3381-3388, 2004.

[31] M. Cai, P. K. Kaiser, H. Uno, Y. Tasaka, and M. Minami, "Estimation of rock mass deformation modulus and strength of jointed hard rock masses using the GSI system," International Journal of Rock Mechanics \& Mining Sciences, vol. 41, no. 1, pp. 3-19, 2004.

[32] H. Saroglou and G. Tsiambaos, "A modified Hoek-Brown failure criterion for anisotropic intact rock," International Journal of Rock Mechanics and Mining Sciences, vol. 45, no. 2, pp. 223234, 2008.

[33] K. Wu, Z. Shao, and S. Qin, "An analytical design method for ductile support structures in squeezing tunnels," Archives of Civil and Mechanical Engineering, vol. 20, no. 3, p. 91, 2020.

[34] R. Bertuzzi, K. Douglas, and G. Mostyn, "Improving the GSI Hoek-Brown criterion relationships," International Journal of Rock Mechanics and Mining Sciences, vol. 89, pp. 185-199, 2016.

[35] S. H. Xu, N. Li, G. G. Xu et al., "Thermal transfer and heat balance of saturated rock under freezing-thawing environment," Chinese Journal of Rock Mechanics and Engineering, vol. 35, no. 11, pp. 2225-2236, 2016.
[36] K. Wu, Z. Shao, S. Qin, W. Wei, and Z. Chu, "A critical review on the performance of yielding supports in squeezing tunnels," Tunnelling and Underground Space Technology, vol. 115, article 103815, 2021.

[37] K. Wu, Z. Shao, S. Qin, N. Zhao, and H. Hu, "Analytical-based assessment of effect of highly deformable elements on tunnel lining within viscoelastic rocks," International Journal of Applied Mechanics, vol. 12, no. 3, article 2050030, 2020.

[38] N. Zhao, Z. Shao, K. Wu, Z. Chu, and S. Qin, "Time-dependent solutions for lined circular tunnels considering rockbolts reinforcement and face advancement effects," International Journal of Geomechanics, vol. 21, no. 10, article 04021179, 2021. 